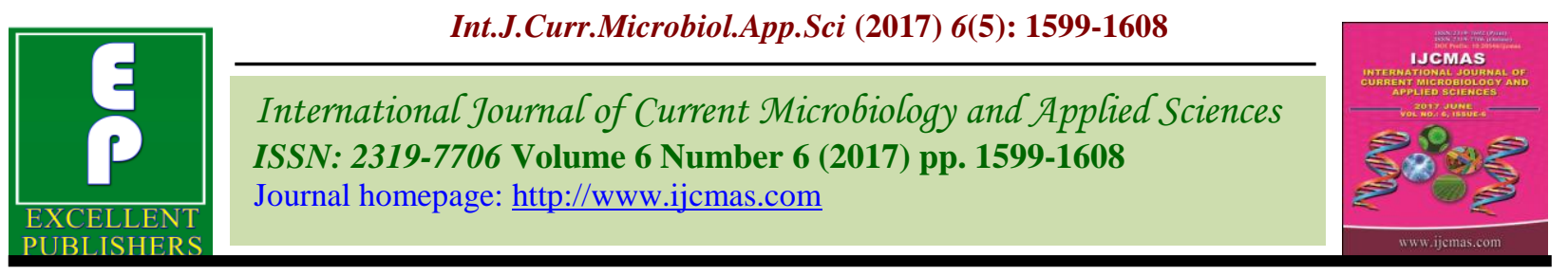

Original Research Article

https://doi.org/10.20546/ijcmas.2017.606.188

\title{
Impact of Abiotic Factors on the Growth and Development of Corcyra cephalonica Stainton in Stored Maize
}

\author{
H.R. Meena, A. Meena, A. Kumar, A.K. Meena*, S.K. Chauhan and B.M. Meena \\ Department of Entomology, Rajasthan College of Agriculture \\ Maharana Pratap University of Agriculture and Technology, Udaipur- 313001, Rajasthan, India \\ *Corresponding author
}

\section{A B S T R A C T}

Keywords

Abiotic, Corcyra

cephalonica,

Temperature,

Relative humidity, Larvae.

Article Info

Accepted:

21 May 2017

Available Online:

10 June 2017
An experiment was conducted in the laboratory to find out the impact of temperature and relative humidity on growth and development of C. cephalonica during, 2010-2011, revealed that the development period of male and female was maximum with a mean of 89.50 and 92.00 days at $20^{\circ} \mathrm{C}$ temperature and 40 per cent relative humidity, respectively. The maximum larval period of (70.10 days) was recorded at $20^{\circ} \mathrm{C}$ temperature and 40 per cent relative humidity; whereas, the maximum weight of full grown larva $(51.00 \mathrm{mg}) \mathrm{was}$ recorded at $30^{\circ} \mathrm{C}$ temperature and 80 per cent relative humidity. The maximum pupal period of male (13.60 days) and female (14.40 days) were observed at $20^{\circ} \mathrm{C}$ temperature and 40 per cent relative humidity, while the higher weight of male $(36.00 \mathrm{mg})$ and female (38.00 mg) pupa were observed at $30^{\circ} \mathrm{C}$ temperature and 80 per cent relative humidity. The maximum adult emergence of male $(61.40 \%)$ and female $(80.90 \%)$ were observed at $30^{\circ} \mathrm{C}$ temperature and 80 per cent relative humidity; whereas, the maximum adult longevity of male (16.30 days) and female (10.50 days) were observed at $20^{\circ} \mathrm{C}$ temperature and 40 per cent relative humidity. The maximum growth rate index of male (1.35) and female (1.64) were recorded at $30^{\circ} \mathrm{C}$ temperature and 80 per cent relative humidity, while minimum growth rate index male $(0.39)$ and female $(0.60)$ were observed at $20^{\circ} \mathrm{C}$ temperature and 40 per cent relative humidity.

\section{Introduction}

Maize (Zea mays L) is one of the most versatile emerging crops having wider adaptability under varied agro-climatic conditions. Globally, maize is known as queen of cereals because it has the highest genetic yield potential among the cereals. It is cultivated on nearly $150 \mathrm{~m}$ ha in about 160 countries having wider diversity of soil, climate, biodiversity and management practices. The average productivity in India is 2.5 tone/ ha (IMS, 2014). In India, maize is the third most important food crops after rice and wheat. Maize in India, contributes nearly 9 per cent in the national food basket. In addition to staple food for human being and quality feed for animals, maize serves as a basic raw material as an ingredient to thousands of industrial products that includes starch, oil, protein, alcoholic beverages, food sweeteners, pharmaceutical, cosmetic, film, textile, gum, package and paper industries etc. The maize is cultivated throughout the year in all states of the country for various purposes including grain, fodder, green cobs, sweet 
corn, baby corn and pop corn in peri-urban areas. The predominant maize growing states that contributes more than 80 per cent of the total maize production are Andhra Pradesh (20.9\%), Karnataka (16.5\%), Rajasthan (9.9 $\%)$, Maharashtra (9.1\%), Bihar (8.9\%), Uttar Pradesh (6.1\%), Madhya Pradesh (5.7\%) and Himachal Pradesh (4.4\%). Apart from these states maize is also grown in Jammu and Kashmir and North-Eastern states. In Rajasthan, maize is mostly grown in Banswara, Udaipur, Bhilwara, Dungarpur, Rajsamand and Chittorgarh districts.

Although, there are about 200 species of insects and mites are found infesting maize grains, few of which are major or primary pests. Among these, the rice moth, Corcyra cephalonica (Stainton) (Lepidoptera: Pyralidae) is one of the most important pest of stored maize. Corcyra cephalonica (Stainton), popularly known as the "Rice meal moth" or the "flour moth". The earlier reference of this insect was made by Stainton (1866), who provisionally named it Melissoblaptes cephalonica giving a brief description. Later a new genus, Corcyra was erected by Rogonot (1885) to accommodate this insect, the name being derived from the ancient name of "Corfu", where it was presumed to have been imported into England. According to Chittenden (1919), though Corcyra is known to occur many parts of Europe, Asia and America. It feeds on many hosts, viz., rice, sorghum, wheat, groundnut, gram, cotton seed, etc. The larvae cause damage to grain by feeding under silken webs. When infestation is high the entire stock of grain may converted into a webbed mass. Ultimately, a characteristic fowl odour is developed and the grain rendered unfit for human consumption. The pest cause both quantitative and qualitative losses.

In order to develop economic and effective control measures for $C$. cephalonica, detailed and accurate knowledge of its bio-ecology is essential under variable macro-ecological conditions which would be helpful in the possible prediction of population levels and study the various mortality factors regulating pest abundance so that an effective management strategy may be developed. These aspects need more intensive investigations, as abiotic factors such as temperature, relative humidity and moisture percentage of stored products play vital role in pest infestation. Temperature mediated physiological actions regulate population dynamics. The effect of humidity on the development of host insect is almost intimately associated with that of temperature and operations indirectly through the moisture content of grains. These parameters ultimately shows their effect on the feeding ability and getting good quality eggs through enhanced nourishment of Corcyra larvae. One of the eco-friendly and economic approaches to keep the stored food grains free from insect attack, thus the present study were undertaken to find out the role of different temperature and the relative humidity levels and their combined effect on some biological parameters of C. cephalonica.

\section{Materials and Methods}

The present experiment was carried out on mainly two parameters i.e., temperature and relative humidity under laboratory conditions for their effect on growth and development of C. cephalonica at Bio-control Research Laboratory, Department of Entomology, Rajasthan College of Agriculture, MPUAT, Udaipur during 2010. Biological studies of $C$. cephalonica were undertaken at three different temperatures and humidity levels. Two hundred gram conditioned maize grain as described in the maintenance of insect culture were taken in plastic containers (230x75mm). Twenty newly hatched larvae of $C$. cephalonica were released in containers. 
These containers were kept in different BOD incubators, which were fixed temperatures of $20^{\circ} \mathrm{C}, 30^{\circ} \mathrm{C}$ and $40^{\circ} \mathrm{C}$ with variable relative humidity i.e. 40, 60, 80 per cent. Every day grains were checked. Observations were recorded on developmental period (body weight, larval and pupal period), adult emergence (male and female), adult longevity and growth rate index. In order to obtain eggs, to study the development period, the folded black thick papers were introduced into culture jars containing 1 to 2 days old $C$. cephalonica adult moths. After 24 hours, the black thick papers were removed and unfolded. The black thick paper bearing 50 eggs was cut and kept in petri dish. The pieces of black paper were removed from the petri dish and the eggs were carefully examined for hatching under a binocular microscope. The incubation period worked out by recording the date of egg laying and date of egg hatching. The freshly hatched larvae were released in each replication for the study of development of $C$. cephalonica and observations were continued till the adult emergence ceased. The larval period was worked out by recording the date of hatching and date of formation of silken web in the food. The period between web formation and adult emergence was considered as pupal period. Larval and pupal weight was determined with help of electronic balance. Longevity of male and female adults was determined by recording the date of their emergence from pupae and the date of natural death. The growth rate index was worked out with the help of following formula:

Growth Rate Index $=$ Percent adult emergence

Total development period

\section{Results and Discussions}

Temperature is an important component of the environment and the rate of metabolism, growth, development, reproduction, general behavior and distribution of insect pests are largely controlled by it. Fields (1992) proposed lethal, sub-lethal and optimal temperature ranges for many stored product insects; $25-33^{\circ} \mathrm{C}$ is optimal for growth and reproduction, while; $13-25^{\circ} \mathrm{C}$ or $33-35^{\circ} \mathrm{C}$ are sub-optimal at which insects are able to complete their development and produces offspring, and lastly at $<13^{\circ}$ or $>35^{\circ} \mathrm{C}$ insects eventually die. Changes in metabolic rate caused by fluctuations of temperature have a direct bearing on two important aspects of insect life cycles; one is locomotion for performing crucial activities such as mating and feeding and the other is growth represented by development and metamorphosis. Thus, temperature mediated physiological actions regulate population dynamics. The effect of humidity on the development of storage pest is almost intimately associated with that of temperature and operates indirectly through the moisture content of grains. With regard to biology, reproductive potentiality and development of C. cephalonica some work has been carried out on different temperatures and relative humidities in different countries of the world (Kamel and Hassanein, 1967; Teotia and singh, 1975; pajni et al., 1978; Meena and Bhargava, 2010 and Chaubey and Misra, 2011).

\section{Developmental period of female and male}

The data on the effect of temperature and relative humidity interaction of both the factors on the development period of female and mele have been presented in table 1 . The development period of test insect varied with the temperature. The development period was maximum of 87.53 days at $20^{\circ} \mathrm{C}$ and minimum of 42.83 days was recorded at $40^{\circ} \mathrm{C}$ temperature. The data obtained on the effect of relative humidity revealed that the test insect took maximum 67.13 days to complete 
their development at 40 per cent relative humidity and it was minimum of 52.57 days at 80 per cent relative humidity. The present studies on effect of temperature and relative humidity revealed that the developmental period of $C$. cephalonica was 92.00 days at $20^{\circ} \mathrm{C}$ temperature and 40 per cent relative humidity. Whereas, the minimum development period of the test insect 31.30 days was recorded at $40^{\circ} \mathrm{C}$ temperature and 80 per cent relative humidity. The maximum development period of male i.e. 84.60 days was recorded at $20^{\circ} \mathrm{C}$ and minimum 40.00 days was recorded at $40^{\circ} \mathrm{C}$ temperature. The data obtained on the effect of relative humidity revealed that the test insect took maximum 64.40 days to complete their development at 40 per cent relative humidity and it was minimum of 49.30 days at 80 per cent relative humidity. The present studies on effect of temperature and relative humidity revealed that the developmental period of $C$. cephalonica was 89.50 days at $20^{\circ} \mathrm{C}$ temperature and 40 per cent relative humidity. Whereas, the minimum development period of the test insect 33.70 days was recorded at $40^{\circ} \mathrm{C}$ temperature and 80 per cent relative humidity. This finding is in close conformity with the findings of Jagdish et al., (2009) reported the total developmenatal period of $C$. cephalonica occupied, 41 to 59 days on foxtail millet at a temperature of $24-28^{\circ} \mathrm{C}$ and $70 \%$ relative humidity. Russell et al., (1980) reported that at 70 per cent relative humidity and $28^{\circ} \mathrm{C}$ temperature, developmental period were 40 and 41 days for males and females, respectively. Allotey and Azalekor (2000) observed that at temperature ranging from $27.5-30^{\circ} \mathrm{C}$ and relative humidity from $60-73$ per cent the mean developmental period ranged from $33.2 \pm 0.2$ to $45.3 \pm 1.8$ days. Similarily, the mean developmental period of C. cephalonica ranged from 46.5 to 77 days at $25.5^{\circ} \mathrm{C}$ temperature and 75 per cent relative humidity this finding was also supported by Kamel and Hassanein (1967). reported that mean larval period was 66.40 days at $15^{\circ} \mathrm{C}$ which it was lowest of 24.5 days at $30^{\circ} \mathrm{C}$ temperature.

\section{Larval period}

The influences of temperature and relative humidity on larval development have been presented in (Table 2) revealed that the larva period was maximum of 63.73 days at $20^{\circ} \mathrm{C}$ and it was minimum of 33.90 days at $40^{\circ} \mathrm{C}$ temperature. The data obtained on the effect of relative humidity revealed that the test insect took maximum 57.05 days to complete their larval period at 40.per cent relative humidity and minimum 38.60 days was taken by the test insect to complete their larval period at 80 per cent relative humidity. The present studies on effect of temperature and relative humidity revealed that the maximum larval period of C. cephalonica i.e. 70.10 days was at $20^{\circ} \mathrm{C}$ temperature and 40 per cent relative humidity, Whereas, the minimum larval period of the test insect 22.70 days was recorded at $40^{\circ} \mathrm{C}$ temperature and 80 per cent relative humidity. This finding is in close conformity with the findings of Hugar and jai rao (1985) found highest larval period 66.40 days at $15^{\circ} \mathrm{C}$ lowest larval period 24.50 days at $30^{\circ} \mathrm{C}$ temperature.

\section{Weight of full grown larva}

Results obtained with regard to weight of full grown larvae at different levels of temperature and relative humidity have been presented in table 3 . The larval weight found to be highest $46.33 \mathrm{mg}$. when the insect was reared at $30^{\circ} \mathrm{C}$ and lowest larval weight of $37.00 \mathrm{mg}$. was observed at $20^{\circ} \mathrm{C}$ temperature. The data obtained on the effect of relative humidity revealed that the maximum larval weight of $44.67 \mathrm{mg}$ was recorded at 80 per cent relative humidity and minimum 38.33 mg was observed at 40 per cent relative humidity. The combined effect of temperature 
and relative humidity showed that most suitable combination for weight of full grown larva was $30^{\circ} \mathrm{C}$ temperature and 80 per cent relative humidity on which maximum weight of $51.00 \mathrm{mg}$ was recorded. While, the lowest larval weight $33.00 \mathrm{mg}$. was observed at $20^{\circ} \mathrm{C}$ temperature and 40 per cent relative humidity. Similar results were also obtained by Meena and Bhargava 2010 found that temperature of $30^{\circ} \mathrm{C}$ and relative humidity 70 per cent was the most suitable combination of which maximum weight of full grown larva $(0.09 \mathrm{~g}$.) was recorded.

\section{Pupal Period of female and male}

The data obtained on the effect of temperature and relative humidity on the duration of pupal stage of female and male have been presented in table 4 . The pupal period of female varied with the temperature. The maximum pupal period of 13.40 days of female was found at $20^{\circ} \mathrm{C}$ and minimum of 10.50 days at $30^{\circ} \mathrm{C}$ temperature. The data obtained on the effect of relative humidity revealed that the test insect took maximum 12.60 days to complete their pupal period at 40 per cent relative humidity, while minimum 10.78 days was observed at 80 per cent relative humidity. The present studies on effect of temperature and relative humidity revealed that the maximum pupal period of $C$. cephalonica 14.40 days was observed at temperature $20^{\circ} \mathrm{C}$ and 40 per cent relative humidity, Whereas, the minimum pupal period of the test insect i.e. 9.85 days was recorded at $30^{\circ} \mathrm{C}$ temperature and 80 per cent relative humidity. The pupal period of male also varied with the temperature. The pupal period of male was maximum of 12.30 days at $20^{\circ} \mathrm{C}$ and it was minimum of 9.27 days at $30^{\circ} \mathrm{C}$ temperature. The data obtained on the effect of relative humidity revealed that the test insect took maximum 11.67 days to complete their pupal period at 40 per cent relative humidity and minimum 9.80 days was observed at 80 per cent relative humidity. The present studies on effect of temperature and relative humidity revealed that the maximum pupal period of $C$. cephalonica 13.60 days was observed at temperature $20^{\circ} \mathrm{C}$ and 40 per cent relative humidity, Whereas, the minimum pupal period of the test insect i.e. 8.40 days was recorded at $30^{\circ} \mathrm{C}$ temperature and 80 per cent relative humidity. This finding is in close conformity with the findings of Ray (1994). reported that the pupal period of $C$. cephalonica on maize at $28 \pm 1^{\circ} \mathrm{C}$ and $\mathrm{RH} 75$ per cent was recorded 10 days. Hugar et al., (1990) reported that the pupal period decreased with increase in temperature and humidity, being longest at $15^{\circ} \mathrm{C}$ and shortest at $35^{\circ} \mathrm{C}$.

\section{Pupal weight of female and male}

The mean weight of mature pupa recorded at different temperture and relative humidity have been presented in table 5 the data revealed that the higher pupal weight 35.67 mg of female pupae was recorded when the insect was reared at $30^{\circ} \mathrm{C}$ and it was lowest of $25.67 \mathrm{mg}$ at $20^{\circ} \mathrm{C}$ temperature. The data obtained on the effect of relative humidity revealed that the mean pupal weight was maximum of $33.33 \mathrm{mg}$ at 80 per cent relative humidity and was minimum i.e. $28.33 \mathrm{mg}$ at 40 per cent relative humidity. The combined effect of temperature and relative humidity showed that most suitable combination for gaining the higher weight of pupa was $30^{\circ} \mathrm{C}$ temperature and 80 per cent relative humidity at which maximum weight of $38.00 \mathrm{mg}$ was recorded. Lowest pupal weight of $23.00 \mathrm{mg}$ was observed at $20^{\circ} \mathrm{C}$ temperature and 40 per cent relative humidity. The pupal weight of male was highest of $33.00 \mathrm{mg}$ when the insect was reared at $30^{\circ} \mathrm{C}$ and it was lowest of 23.00 $\mathrm{mg}$ at $20^{\circ} \mathrm{C}$ temperature. The data obtained on the effect of relative humidity revealed that the mean pupal weight was maximum of $31.00 \mathrm{mg}$ at 80 per cent relative humidity and 
was minimum i.e. $26.00 \mathrm{mg}$ at 40 per cent relative humidity. The combined effect of temperature and relative humidity showed that most suitable combination for gaining the higher weight of pupa was $30^{\circ} \mathrm{C}$ temperature and 80 per cent relative humidity at which maximum weight of $36.00 \mathrm{mg}$ was recorded. Lowest pupal weight of $21.00 \mathrm{mg}$. was observed at $20^{\circ} \mathrm{C}$ temperature and 40 per cent relative humidity. Similar findings were also reported by Meena and Bhargava (2010) and reported that a combination of $30^{\circ} \mathrm{C}$ temperature and 70 per cent was most suitable for the pupa to gain optimum weight.

\section{Adult emergence of female and male}

The data presented in table 6 showed that the maximum adult emergence of female was recorded $(72.90 \%)$ when insects were reared at $30^{\circ} \mathrm{C}$ and minimum adult emergence $(60.67 \%)$ was observed at $20^{\circ} \mathrm{C}$ temperature. The data obtained on the effect of relative humidity revealed that the maximum adult emergence $(71.92 \%)$ was at 80 per cent relative humidity and it was minimum $(59.20 \%)$ at 40 per cent relative humidity. The combined effect of temperature and relative humidity showed that a combination $30^{\circ} \mathrm{C}$ temperature and 80 per cent relative humidity was most suitable at which maximum adult emergence $(80.90 \%)$ was observed, while minimum adult emergence (54.90\%) was observed at $20^{\circ} \mathrm{C}$ temperature and 40 per cent relative humidity. The maximum 53.40 per cent and minimum adult emergence $39.73 \%$ was recorded when insect was reared at $30^{\circ} \mathrm{C}$ and $20^{\circ} \mathrm{C}$ temperature, respectively. The data obtained on the effect of relative humidity revealed that the maximum $(52.20 \%)$ and minimum adult emergence $(40.23 \%)$ was recorded at 80 per cent and 40 per cent relative humidity, respectively. The combined effect of temperature and relative humidity showed that a combination $30^{\circ} \mathrm{C}$ temperature and 80 per cent relative humidity was most suitable at which maximum adult emergence $(61.40 \%)$ was observed. While, minimum adult emergence $(35.10 \%)$ was observed at $20^{\circ} \mathrm{C}$ temperature and 40 per cent relative humidity. These observations are in conformity with the findings of Hugar et al., (1990). He reported that maximum adult emergence at optimum temperature (25 $30^{\circ} \mathrm{C}$ ) and least at $15^{\circ} \mathrm{C}$ and it was less pronounced by relative humidity. Allotey and Azalekor (1999) reported 67.5 per cent adult emergence at $27-30^{\circ} \mathrm{C}$ and $60-73$ per cent relative humidity.

\section{Longevity of male and female adult}

The longevity of male and female adults recorded at different levels of temperature and relative humidity have been present in table 7 reveals that the longevity of male and female adults indicate that it increases with the decrease in temperature. The maximum longevity of male and female of 12.83 and 9.92 days was recorded at $20^{\circ} \mathrm{C}$ temperature, respectively. Longevity of male and female adults was Minimum of 3.16 and 2.99 days, respectively at $40^{\circ} \mathrm{C}$ temperature.

The humidity also seemed to have effect on the longevity of male and female adults whereas maximum longevity of male and female 8.89 and 6.30 days was observed at 40 per cent relative humidity, respectively, whereas minimum longevity of male and female 6.32 and 5.60 at 80 per cent relative humidity, respectively. The effect of both factors on longevity of male and female adults showed that the longevity of adult was maximum at $20^{\circ} \mathrm{C}$ and 40 per cent relative humidity combinations, and it was minimum at $40^{\circ} \mathrm{C}$ and 60 per cent relative humidity. This finding is in close conformity with the findings of Cox et al., (1981) reported that the life span of $C$. cephalonica increased with decreasing temperature between 20 and $35^{\circ} \mathrm{C}$. 
Table.1 Effect of temperature and relative humidity on the development of C. cephalonica

\begin{tabular}{|c|c|c|c|c|c|c|c|c|}
\hline \multirow{4}{*}{$\begin{array}{l}\text { Relative } \\
\text { humidity (\%) }\end{array}$} & \multicolumn{8}{|c|}{ Developmental period (days) } \\
\hline & \multicolumn{4}{|c|}{ Female } & \multicolumn{4}{|c|}{ Male } \\
\hline & \multicolumn{3}{|c|}{ Temperature $\left({ }^{\circ} \mathrm{C}\right)$} & \multirow{2}{*}{ Mean } & \multicolumn{3}{|c|}{ Temperature $\left({ }^{\circ} \mathbf{C}\right)$} & \multirow[t]{2}{*}{ Mean } \\
\hline & 20 & 30 & 40 & & 20 & 30 & 40 & \\
\hline 40 & 92.00 & 56.30 & 53.10 & 67.13 & 89.50 & 53.40 & 50.30 & 64.40 \\
\hline 60 & 90.30 & 36.56 & 44.10 & 56.99 & 87.40 & 35.10 & 36.00 & 52.83 \\
\hline 80 & 80.30 & 46.10 & 31.30 & 52.57 & 76.90 & 37.30 & 33.70 & 49.30 \\
\hline Mean & 87.53 & 46.32 & 42.83 & & 84.60 & 41.93 & 40.00 & \\
\hline S.Em. \pm & \multicolumn{4}{|c|}{0.877} & \multicolumn{4}{|c|}{0.876} \\
\hline C.D. $(P=0.05)$ & \multicolumn{4}{|c|}{2.546} & \multicolumn{4}{|c|}{2.543} \\
\hline
\end{tabular}

Table.2 Effect of temperature and relative humidity on the larval period of $C$. cephalonica

\begin{tabular}{|c|c|c|c|c|}
\hline \multirow{2}{*}{$\begin{array}{c}\text { Relative humidity } \\
(\%)\end{array}$} & \multicolumn{4}{|c|}{ Larval period (days) } \\
\cline { 2 - 5 } & $\mathbf{2 0}$ & $\mathbf{3 0}$ & $\mathbf{4 0}$ & \multirow{2}{*}{ Mean } \\
\hline $\mathbf{4 0}$ & 70.10 & 55.85 & 45.20 & 57.05 \\
\hline $\mathbf{6 0}$ & 65.10 & 24.60 & 33.80 & 41.17 \\
\hline $\mathbf{8 0}$ & 56.00 & 37.10 & 22.70 & 38.60 \\
\hline Mean & 63.73 & 39.18 & 33.90 & \\
\hline S.Em. \pm & $\mathbf{1 . 3 6 1}$ & \multicolumn{3}{|}{} \\
\hline C.D. $(\mathbf{P = 0 . 0 5})$ & $\mathbf{3 . 9 4 9}$ & \multicolumn{4}{|c|}{} \\
\hline
\end{tabular}

Table.3 Effect of temperature and relative humidity on weight of full grown larva of C. cephalonica

\begin{tabular}{|c|c|c|c|c|}
\hline \multirow{2}{*}{$\begin{array}{c}\text { Relative humidity } \\
(\boldsymbol{\%})\end{array}$} & \multicolumn{4}{|c|}{ Weight of full grown larva (mg) } \\
\cline { 2 - 5 } & $\mathbf{2 0}$ & $\mathbf{3 0}$ & $\mathbf{4 0}$ & \multirow{2}{*}{ Mean } \\
\hline $\mathbf{4 0}$ & 33.00 & 42.00 & 40.00 & 38.33 \\
\hline $\mathbf{6 0}$ & 38.00 & 46.00 & 41.00 & 41.67 \\
\hline $\mathbf{8 0}$ & 40.00 & 51.00 & 43.00 & 44.67 \\
\hline Mean & 37.00 & 46.33 & 41.33 & \\
\hline S.Em. \pm & $\mathbf{0 . 7 2 6}$ & & & \\
\hline C.D. $(\mathbf{P}=\mathbf{0 . 0 5})$ & $\mathbf{2 . 1 0 6}$ & \multicolumn{3}{|}{} \\
\hline
\end{tabular}


Table.4 Effect of temperature and relative humidity on the pupal period of $C$. cephalonica

\begin{tabular}{|c|c|c|c|c|c|c|c|c|}
\hline \multirow{4}{*}{$\begin{array}{c}\text { Relative } \\
\text { humidity } \\
(\%)\end{array}$} & \multicolumn{8}{|c|}{ Pupal period (days) } \\
\hline & \multicolumn{4}{|c|}{ Female } & \multicolumn{4}{|c|}{ Male } \\
\hline & \multicolumn{3}{|c|}{ Temperature $\left({ }^{\circ} \mathbf{C}\right)$} & \multirow{2}{*}{ Mean } & \multicolumn{3}{|c|}{ Temperature $\left({ }^{\circ} \mathbf{C}\right)$} & \multirow[t]{2}{*}{ Mean } \\
\hline & 20 & 30 & 40 & & 20 & 30 & 40 & \\
\hline 40 & 14.40 & 11.29 & 12.10 & 12.60 & 13.60 & 10.30 & 11.10 & 11.67 \\
\hline 60 & 13.50 & 10.35 & 11.30 & 11.72 & 12.10 & 9.10 & 10.30 & 10.50 \\
\hline 80 & 12.30 & 9.85 & 10.20 & 10.78 & 11.20 & 8.40 & 9.80 & 9.80 \\
\hline Mean & 13.40 & 10.50 & 11.20 & & 12.30 & 9.27 & 10.40 & \\
\hline S.Em. \pm & \multicolumn{4}{|c|}{0.205} & \multicolumn{4}{|c|}{0.187} \\
\hline C.D. $(P=0.05)$ & \multicolumn{4}{|c|}{0.594} & \multicolumn{4}{|c|}{0.542} \\
\hline
\end{tabular}

Table.5 Effect of temperature and relative humidity on pupal weight of $C$. cephalonica

\begin{tabular}{|c|c|c|c|c|c|c|c|c|}
\hline \multirow{4}{*}{$\begin{array}{c}\text { Relative } \\
\text { humidity } \\
(\%)\end{array}$} & \multicolumn{8}{|c|}{ Pupal weight (mg) } \\
\hline & \multicolumn{4}{|c|}{ Female } & \multicolumn{4}{|c|}{ Male } \\
\hline & \multicolumn{3}{|c|}{ Temperature $\left({ }^{\circ} \mathrm{C}\right)$} & \multirow{2}{*}{ Mean } & \multicolumn{3}{|c|}{ Temperature $\left({ }^{\circ} \mathrm{C}\right)$} & \multirow[t]{2}{*}{ Mean } \\
\hline & 20 & 30 & 40 & & 20 & 30 & 40 & \\
\hline 40 & 23.00 & 34.00 & 28.00 & 28.33 & 21.00 & 31.00 & 26.00 & 26.00 \\
\hline 60 & 25.00 & 35.00 & 31.00 & 30.33 & 22.00 & 32.00 & 27.00 & 27.00 \\
\hline 80 & 29.00 & 38.00 & 33.00 & 33.33 & 26.00 & 36.00 & 31.00 & 31.00 \\
\hline Mean & 25.67 & 35.67 & 30.73 & & 23.00 & 33.00 & 28.00 & \\
\hline S.Em. \pm & \multicolumn{4}{|c|}{0.538} & \multicolumn{4}{|c|}{0.493} \\
\hline C.D. $(P=0.05)$ & \multicolumn{4}{|c|}{1.560} & \multicolumn{4}{|c|}{0.142} \\
\hline
\end{tabular}

Table.6 Effect of temperature and relative humidity on the adult emergence of $C$. cephalonica

\begin{tabular}{|c|c|c|c|c|c|c|c|c|}
\hline \multirow{4}{*}{$\begin{array}{c}\text { Relative } \\
\text { humidity } \\
(\%)\end{array}$} & \multicolumn{8}{|c|}{ Adult emergence (\%) } \\
\hline & \multicolumn{4}{|c|}{ Female } & \multicolumn{4}{|c|}{ Male } \\
\hline & \multicolumn{3}{|c|}{ Temperature $\left({ }^{\circ} \mathrm{C}\right)$} & \multirow{2}{*}{ Mean } & \multicolumn{3}{|c|}{ Temperature $\left({ }^{\circ} \mathbf{C}\right)$} & \multirow[t]{2}{*}{ Mean } \\
\hline & 20 & 30 & 40 & & 20 & 30 & 40 & \\
\hline 40 & $\begin{array}{c}54.90 \\
(47.81)\end{array}$ & $\begin{array}{c}62.70 \\
(52.36)\end{array}$ & $\begin{array}{c}60.00 \\
(50.77)\end{array}$ & $\begin{array}{c}59.20 \\
(50.31)\end{array}$ & $\begin{array}{c}35.10 \\
(36.33)\end{array}$ & $\begin{array}{c}42.60 \\
(40.74)\end{array}$ & $\begin{array}{c}43.00 \\
(40.98)\end{array}$ & $40.23(39.34)$ \\
\hline 60 & $\begin{array}{c}62.30 \\
(52.13)\end{array}$ & $\begin{array}{c}75.10 \\
(60.08)\end{array}$ & $\begin{array}{c}71.40 \\
(57.69)\end{array}$ & $\begin{array}{c}69.60 \\
(56.63)\end{array}$ & $\begin{array}{c}41.52 \\
(40.12)\end{array}$ & $\begin{array}{c}56.20 \\
(48.56)\end{array}$ & $\begin{array}{c}52.30 \\
(46.32)\end{array}$ & $50.07(45.00)$ \\
\hline 80 & $\begin{array}{c}65.10 \\
(53.80)\end{array}$ & $\begin{array}{c}80.90 \\
(64.09)\end{array}$ & $\begin{array}{c}69.75 \\
(56.63)\end{array}$ & $\begin{array}{c}71.92 \\
(58.17)\end{array}$ & $\begin{array}{c}42.56 \\
(40.72)\end{array}$ & $\begin{array}{c}61.40 \\
(51.59)\end{array}$ & $\begin{array}{c}54.50 \\
(47.58)\end{array}$ & $52.82(46.63)$ \\
\hline Mean & $\begin{array}{c}60.67 \\
(51.25)\end{array}$ & $\begin{array}{c}72.90 \\
(58.84)\end{array}$ & $\begin{array}{c}67.05 \\
(55.03)\end{array}$ & & $\begin{array}{c}39.73 \\
(39.05)\end{array}$ & $\begin{array}{c}53.40 \\
(46.97)\end{array}$ & $\begin{array}{c}49.93 \\
(44.96)\end{array}$ & \\
\hline S. Em. \pm & \multicolumn{4}{|c|}{0.541} & \multicolumn{4}{|c|}{0.359} \\
\hline C.D. $(P=0.05)$ & \multicolumn{4}{|c|}{1.570} & \multicolumn{4}{|c|}{1.041} \\
\hline
\end{tabular}

Figure in parenthesis shows the angular transformed values of the respective values 
Table.7 Effect of temperature and relative humidity on adult longevity of $C$. cephalonica

\begin{tabular}{|c|c|c|c|c|c|c|c|c|}
\hline \multirow{4}{*}{$\begin{array}{c}\text { Relative } \\
\text { humidity } \\
(\%)\end{array}$} & \multicolumn{8}{|c|}{ Adult longevity (Days) } \\
\hline & \multicolumn{4}{|c|}{ Female } & \multicolumn{4}{|c|}{ Male } \\
\hline & \multicolumn{3}{|c|}{ Temperature $\left({ }^{\circ} \mathbf{C}\right)$} & \multirow{2}{*}{ Mean } & \multicolumn{3}{|c|}{ Temperature $\left({ }^{\circ} \mathrm{C}\right)$} & \multirow[t]{2}{*}{ Mean } \\
\hline & 20 & 30 & 40 & & 20 & 30 & 40 & \\
\hline 40 & 10.50 & 5.20 & 3.20 & 6.30 & 16.30 & 7.10 & 3.28 & 8.89 \\
\hline 60 & 10.00 & 5.00 & 2.95 & 5.98 & 14.20 & 6.80 & 3.15 & 8.05 \\
\hline 80 & 9.25 & 4.75 & 2.81 & 5.60 & 8.00 & 7.80 & 3.05 & 6.28 \\
\hline Mean & 9.92 & 4.98 & 2.99 & & 12.83 & 7.23 & 3.16 & \\
\hline S. Em. \pm & \multicolumn{4}{|c|}{0.242} & \multicolumn{4}{|c|}{0.256} \\
\hline C.D. $(P=0.05)$ & \multicolumn{4}{|c|}{0.701} & \multicolumn{4}{|c|}{0.744} \\
\hline
\end{tabular}

Table.8 Effect of temperature and relative humidity on Growth Rate Index of C. cephalonica

\begin{tabular}{|c|c|c|c|c|c|c|c|c|}
\hline \multirow{4}{*}{$\begin{array}{c}\text { Relative } \\
\text { humidity } \\
(\%)\end{array}$} & \multicolumn{8}{|c|}{ Growth Rate Index } \\
\hline & \multicolumn{4}{|c|}{ Female } & \multicolumn{4}{|c|}{ Male } \\
\hline & \multicolumn{3}{|c|}{ Temperature $\left({ }^{\circ} \mathbf{C}\right)$} & \multirow{2}{*}{ Mean } & \multicolumn{3}{|c|}{ Temperature $\left({ }^{\circ} \mathbf{C}\right)$} & \multirow[t]{2}{*}{ Mean } \\
\hline & 20 & 30 & 40 & & 20 & 30 & 40 & \\
\hline 40 & 0.60 & 1.11 & 1.13 & 0.95 & 0.39 & 0.80 & 0.86 & 0.68 \\
\hline 60 & 0.69 & 1.85 & 1.78 & 1.44 & 0.48 & 1.60 & 1.45 & 1.18 \\
\hline 80 & 0.81 & 1.96 & 1.93 & 1.57 & 0.55 & 1.65 & 1.62 & 1.27 \\
\hline Mean & 0.70 & 1.64 & 1.61 & & 0.47 & 1.35 & 1.31 & \\
\hline S.Em. \pm & \multicolumn{4}{|c|}{0.018} & \multicolumn{4}{|c|}{0.017} \\
\hline C.D. $(P=0.05)$ & \multicolumn{4}{|c|}{0.054} & \multicolumn{4}{|c|}{0.049} \\
\hline
\end{tabular}

Growth Rate Index of female and male

The data recorded on the individual and combined effect of the temperature and relative humidity on the growth rate index of C. cephalonica have been presented in table 8 revealed that the Growth Rate Index of female varied with temperature and relative humidity. The growth rate index was maximum i.e. 1.64 at $30^{\circ} \mathrm{C}$ and minimum 0.70 at $20^{\circ} \mathrm{C}$ temperature. The data obtained on the effect of relative humidity revealed that the maximum Growth Rate Index of 1.57 was recorded at 80 per cent relative humidity and minimum i.e. 0.95 was observed at 40 per cent relative humidity. The present studies on effect of temperature and relative humidity revealed that the maximum growth rate index of C. cephalonica i.e. 1.96 was observed at $30^{\circ} \mathrm{C}$ temperature and 80 per cent relative humidity. Whereas, the minimum Growth
Rate Index of the test insect i.e. 0.60 was recorded at $20^{\circ} \mathrm{C}$ temperature and 40 per cent relative humidity. The Growth Rate Index of male also varied with temperature and relative humidity. The Growth Rate Index of male was maximum i.e. 1.35 at $30^{\circ} \mathrm{C}$ and was minimum of 0.0 .47 at $20^{\circ} \mathrm{C}$ temperature. The data obtained on the effect of relative humidity revealed that the maximum Growth Rate Index of 1.27 was recorded at 80 per cent relative humidity and minimum i.e. 0.68 was observed at 40 per cent relative humidity. The present studies on effect of temperature and relative humidity revealed that the maximum Growth Rate Index of $C$. cephalonica i.e. 1.65 was observed at $30^{\circ} \mathrm{C}$ temperature and 80 per cent relative humidity. Whereas, the minimum Growth Rate Index of the test insect i.e. 0.39 was recorded at $20^{\circ} \mathrm{C}$ temperature and 40 per cent relative humidity. This finding is in close conformity with the 
findings of Cheema et al, 1988. reported that the Growth Rate Index was greatest for larvae of $C$. cephalonica when it was reared at $32^{\circ} \mathrm{C}$ and least for those reared at $27^{\circ} \mathrm{C}$ temperature.

\section{References}

Allotey, J. and Azalekor, W. 2000. Some aspects of the biology and control using botanicals of the rice moth, Corcyra cephalonica Staint. on some pulses. J. Stor. Prod. Res., 36 (3): 235243.

Chaubey, S.N. and Mishra, R. 2011. Temperature induced changes in embryonic biochemistry of Corcyra cephalonica (Stainton) (Lepidoptera: Pyralidae). J. Appl. Biosci., 37(1):56-61.

Cheema, K., Sodhi, S.K., Malhotra, I. and Rose, H.S. 1988. A report on the effect of temperature on the development of Corcyra cephalonica (Stainton) fed on different varieties of raya. Annals Entomol., 6: 59-60.

Chittenden, F. H. 1919. The "Rice Moth", U. S. D. A., Bulletin, No. 783.

Cox, P.D., Crawford, L.A., Gjestrd, G., Bell, C.H. and Bowley, C.R. 1981. The influence of temperature and humidity on the life cycle of Corcyra cephalonica (Stainton) (Lepidoptera: Pyralidae). Bull. Entomol. Res., 71: 1711818.

Fields, P.G. 1992. The control of stored products insects and mites with extreme temperatures. J. Stor. Prod. Res., 28: 89-118.

Hugar, M., Rao, K.J. and Lingappa, S. 1990. Effect of temperature and relative humidity on pupal development and adult emergence of rice moth (Corcyra cephalonica (Stainton). Indian J. Agricult. Sci., 60: 82-84.

Hugar, P. and Jairao, K. 1985. Influence of temperature and relative humidity on larval development and survival of the rice moth, Corcyra cephalonica (Stainton). Madras Agricult. J., 72: 280-283.

Jagadish, P. S. Nirmala, P., Rashmi, M. A., Hedge, J. N. and Neelu Nangia. 2009. Biology of rice moth, Corcyra cephalonica Stainton on foxtail millet. Karnataka $J$. Agricult. Sci., 22(3): 674-675.

Kamel, A.H. and Hassanein, M.H. 1967. Biological studies on Corcyra cephalonica staint. (Coleoptera: Galleriidae). Bulletin de la Societe Entomologique d'Egypte, 51: 175196.

Meena, B.L. and Bhargava, M.C. 2010 ${ }^{\mathrm{a}}$. Influence of temperature and relative humidity on some biological parameters of rice moth, Corcyra cephalonica Stainton. J. Insect Sci. (Ludhiana), 23(2): 160-165.

Pajni, H.R., Rose, H.S. and Gill, K.M. 1978. Some observations on the biology of Corcyra cephalonica Stainton (Lepidoptera: Galleriidae). Res. Bull. Punjab Univ. Sci., 27: 223-224.

Ray, R. 1994. Life table and intrinsic rate of increase of Corcyra cephalonica Stainton on maize. Environ. Ecol., 12: 202-204.

Rogonot, E. L. 1885. Revision of the British species of Phycitidae and Galleriidae. Entomol. Monthly Magaz., 22: 17-32.

Russel, V.M., Schulten, C.G.M. and Roorda, F.A. 1980. Laboratory observations on the development of the rice moth $C$. cephalonica (St.) on millet and sorghum at $28^{\circ} \mathrm{C}$. Zeitschrift fuer Angewandte Entomologie, 89 (5): 488 - 498.

Stainton, H. T. 1866. Description of a new species of family "Galleriidae",

Teotia, T.P.S. and Singh, Y. 1975. Studies on the growth of population of Corcyra cephalonica Stainton. Indian J. Entomology, 37: 227-285. Entomol. Month. Magaz., 2: 172-173.

\section{How to cite this article:}

Meena, H.R., A. Meena, A. Kumar, A.K. Meena, S.K. Chauhan and Meena, B.M. 2017. Impact of Abiotic Factors on the Growth and Development of Corcyra cephalonica Stainton in Stored Maize. Int.J.Curr.Microbiol.App.Sci. 6(6): 1599-1608.

doi: https://doi.org/10.20546/ijcmas.2017.606.188 